DOE/RL-98-80

Revision 0

\title{
An Evaluation of the Management System Verification Pilot \\ at Hanford
}

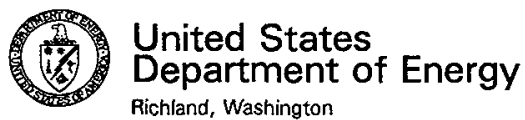

Approved for Public Release 


\section{An Evaluation of the Management System Verification Pilot at Hanford}

Date Published

November 1998

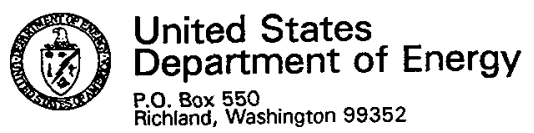

Approved for Public Release 


\section{RELEASE AUTHORIZATION}

Document Number: $\quad$ DOE/RL-98-80, Revision 0

Document Title: $\quad$ Pilot at Hanford

This document, reviewed in accordance with DOE Order 241.1, "Scientific and Technical Information Management," and 241.1-1, "Guide to the Management of Scientific and Technical Information," does not contain classified or sensitive unclassified information and is:

\section{APPROVED FOR PUBLIC RELEASE}

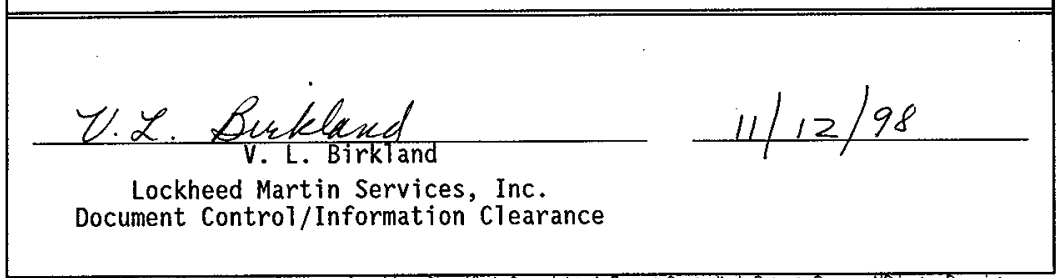

Reviewed for Applled Technology, Business Sensitive, Classified, Copyrighted, Export Controlled, Patent, Personal/Private, Proprietary, Protected CRADA, Trademark, Unclassified Controlled Nuclear Information.

Trademark Disclaimer. Reference herein to any specific commercial product, process, or service by trade name, trademark, manutacturer, or otherwise, does not necessarily constitute or imply its endorsement, recommendation, or favoring by the United States Government or any agency thereof of its contractors or subcontrsctors. The views and opinions of authors expressed herein do not necessarily state or reflect those of the United States Government or any agency thereof. This report has been reproduced from the best available copy.

Printed in the United States of America.

Available to the U.S. Department of Energy and its contractors from the U.S. Department of Energy Otfice of Scientific and Technical Information, P.O. Box 62, Oak Ridge, TN 37831; Telephone: 423/576-8401.

Available to the public from the U.S. Department of Commerce National Technical Information Service, 5285 Port Royal Road, Springfield, VA 22161: Telephone: 703/487-4650. 
DOE/RL-98-80, Rev. 0

FINAL

July 24,1998

\section{AN EVALUATION of the MANAGEMENT SYSTEMS VERIFICATION PILOT at HANFORD}

Co-sponsored by EH-5 and the Office of ESH, Richland Operations

Report Prepared by:

Roger Briggs - Department of Energy Richland Operations Office

Lori Ramonas - Technical Resources International, Inc.

William Westendorf - Link Technologies, Inc. 


\section{TABLE OF CONTENTS}

I. Executive Summary $\ldots \ldots \ldots \ldots \ldots \ldots \ldots \ldots \ldots \ldots \ldots \ldots \ldots \ldots$

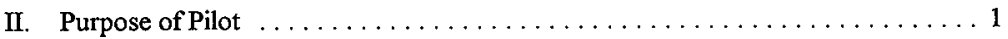

III. General Background

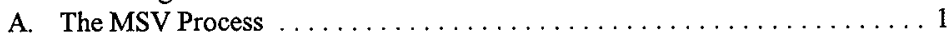

B. DOE Involvement with Chemical Safety and the CMA $\ldots \ldots \ldots \ldots \ldots 2$

IV. Methodology for Hanford's MSV Pilot
A. Context 3
B. Approach

V. Evaluation of Pilot Effectiveness
A. Participant Evaluation Surveys $\ldots \ldots \ldots \ldots \ldots \ldots \ldots \ldots \ldots$
B. Observations of Interview Team $\ldots \ldots \ldots \ldots \ldots \ldots \ldots \ldots \ldots$
C. Summary of CMS Management System Strengths and Opportunities ....... 9

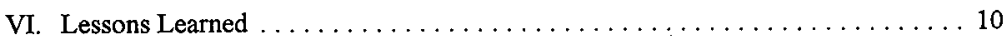

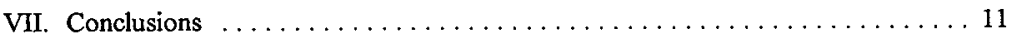

Appendix A - The Responsible Care $\otimes$ Initiative $\ldots \ldots \ldots \ldots \ldots \ldots \ldots \ldots \ldots$

Appendix B - The CMA Management Systems Verification (MSV)

Core Elements and Attributes $\ldots \ldots \ldots \ldots \ldots \ldots \ldots \ldots$

Appendix C - Interview Questions for Hanford's MSV Pilot . . . . . . . . . . 19

Appendix D - MSV Pilot Effectiveness Survey $\ldots \ldots \ldots \ldots \ldots \ldots \ldots \ldots \ldots \ldots \ldots \ldots \ldots \ldots$

Appendix E - Participant Evaluation Surveys - Part I Results $\ldots \ldots \ldots \ldots \ldots 24$

Appendix F - Participant Evaluation Surveys - Part II Results ........... 28 


\section{I, EXECUTIVE SUMMARY}

The Chemical Management System (CMS), currently under development at Hanford, was used as the "test program" for pilot testing the value added aspects of the Chemical Manufacturers Association's (CMA) Management Systems Verification (MSV) process. The MSV process, which was developed by CMA's member chemical companies specifically as a tool to assist in the continuous improvement of environment, safety and health (ESH) performance, represents a commercial sector "best practice" for evaluating ESH management systems.

The primary purpose of Hanford's MSV Pilot was to evaluate the applicability and utility of the MSV process in the Department of Energy (DOE) environment. However, because the Integrated Safety Management System (ISMS) is the framework for ESH management at Hanford and at all DOE sites, the pilot specifically considered the MSV process in the context of a possible future adjunct to Integrated Safety Management System Verification (ISMSV) efforts at Hanford and elsewhere within the DOE complex.

The pilot involved the conduct of two-hour interviews with four separate panels of individuals with functional responsibilities related to the CMS including the Department of Energy Richland Operations (DOE-RL), Fluor Daniel Hanford (FDH) and FDH's major subcontractors (MSCs). A semi-structured interview process was employed by the team of three "verifiers" who directed open-ended questions to the panels regarding the development, integration and effectiveness of management systems necessary to ensure the sustainability of the CMS effort. An "MSV Pilot Effectiveness Survey" also was completed by each panel participant immediately following the interview.

The results of the Effectiveness Survey indicated that the MSV Pilot was particularly beneficial in: 1) focusing on senior management direction, leadership, and accountability; 2) focusing on clear roles and responsibilities; 3 ) focusing on communication and public accountability; and, 4) gauging overall management commitment, all areas that were ranked high in terms of important indicators of management performance. Furthermore, at the request of panel participants, an internal report was generated which identified strengths and opportunities for improvement with respect to the management of the CMS. A brief summary of the findings from this separate effort is included in the body of this report.

The "verifier" team concluded that the MSV Pilot was successful for engaging participants in open-ended and relevant discussion on the management aspects of the CMS as evidenced by: 1) the high level of participation (86\%); 2 ) the active engagement of all panelists during the interview process; and, 3) the energetic and frank nature of discussion that was achieved with each panel that formed the basis of the strengths and opportunities for improvement identified in the CMS MSV Report.

The conclusion drawn by the verifier team, and suggested by panel participants, was that MSV 
DOE/RL-98-80, Rev. 0

may have significant value added as a "front end" process in conjunction with, or associated with internal preparation for, an ISMSV. This conclusion is particularly germane given the strong MSV emphasis on management commitment and involvement and the recommendation of "strengthening management commitment" that emerged from Hanford's recent $\mathrm{K}$ Basins ISMS Phase I Verification effort. 
DOE/RL-98-80, Rev. 0

\section{PURPOSE of PILOT}

The purpose of the Hanford MSV Pilot was to examine the potential "value added" aspects of the chemical manufacturing industry's "best practice" approach for evaluating ESH management systems, called MSV, for possible application to DOE's ISMS verification efforts. The pilot, with its emphasis on management commitment and involvement, was primarily examined in the context of a possible adjunct to the ISMSV particularly since recommendations resulting from the recently conducted $\mathrm{K}$ Basins Phase I Verification at Hanford indicated a need for increased management attention, resources and involvement with respect to ISMS implementation. However, it is possible that under certain circumstances it may be most beneficial to apply the MSV process as a stand alone effort.

\section{GENERAL BACKGROUND}

\section{A. The MSV Process}

To understand the context of the MSV process, it is necessary to understand the overall framework into which it fits, Responsible Care $B$. Responsible Care $\otimes$ is an initiative of the U.S. chemical manufacturing industry. It was launched in 1988 by CMA as an industry-wide response to escalating public concerns about ESH practices of the chemical industry following the Bhopal accident in December, 1984. The CMA is a non-profit trade association whose approximately 195 member companies account for more than 90 percent of basic industrial chemical production in the United States. The focus of Responsible Care $B$ is to continually improve the performance of the chemical industry in the areas of ESH stewardship and to be responsive to public concerns about the industry's overall management of chemicals. Additional background information on Responsible Care $\otimes$ can be found in $A P P E N D I X A$.

The Responsible Care MSV process is built around a verification protocol or guidance document which organizes the verification into a general sequence of steps which examine five core areas: 1) Policy and Leadership; 2) Planning; 3) Implementation, Operation, and Accountability; 4) Performance Measurement and Corrective Action; and 5) Management Review and Reporting. These core areas are identical to the five identified for ISO 14000.

Sub-divided within the five core areas CMA delineates 35 "attributes". These "attributes" are the necessary systems, organization, policies, programs, etc. that support each core area of the management system and are the basis for the evaluation of the overall management system. Evidence of the existence of these attributes and their integration into the company's operations and culture is the focus of the MSV process. The 35 attributes of the MSV process, which formed the basis of the specific questions developed for the MSV Pilot, are listed in APPENDIX B. The MSV does not replace but rather complements the more 
traditional audit/self-assessment practices that continue in place at most chemical facilities. In the Responsible Care $\otimes$ MSV process, industry peers, with experience in management systems, accompanied by community representatives, first conduct a disciplined and comprehensive review of the necessary documentation (policies, programs, procedures) which forms the underlying foundation of the ESH management system. Then the industry peers and community representatives engage in a series of open-ended interviews with company personnel to determine whether a company indeed has appropriate, functioning and sustainable management systems in place. Through this combined documentation review and panel interview observation process, the industry peers and community representatives are able to identify strengths and areas for improvement in the company's management systems. These findings are submitted to the company being verified (and ONLY to the company being verified) in a final written report.

\section{B. DOE Involvement with Chemical Safety and the CMA}

In February 1994, Secretary O'Leary initiated a vulnerability review of chemical safety at DOE sites. The review, which was completed in July 1994 and involved the evaluation of 146 facilities at 29 sites across the DOE complex, identified eight generic vulnerabilities and generic management weaknesses in five programmatic areas. To address these findings a management response plan was developed by the Assistant Secretary for Environment, Safety and Health and endorsed by all of the Department's Cognizant Officers. The response plan highlighted industry partnerships as key to improving safety at DOE sites and specifically referenced Responsible Care $B$ as an exemplary industry initiative in chemical safety.

Since 1994, applying chemical industry best practices for chemical safety to DOE sites has been part of an ongoing, focused effort by DOE's Office of the Deputy Assistant Secretary for Worker Health and Safety (EH-5). This effort was formalized in an August 1996 Memorandum of Understanding between DOE and the CMA which encourages the sharing of exemplary policies, procedures and practices for continuous improvement in ESH.

The Hanford site has had a long standing involvement with chemical industry networking and bench-marking in the area of ESH continuous improvement. Recent examples include:

1. Participation in conference calls with Ashland Chemical Company (Fall, 1996) on the development, implementation and evaluation of integrated ESH management systems;

2. Sponsorship of a Rohm \& Haas Company visit to the site (Spring, 1997) to examine the application of chemical industry best practices in integrated ESH management systems to the site's evolving ISMS effort; and, 
3. Incorporation of key Responsible Care 8 -related guiding principles on "management commitment" and "community involvement/outreach" into the site's final ISMS framework (Fall, 1997).

4. Development of a state-of-the-art CMS framework for the site based on benchmarking with and assistance from DuPont.

The MSV Pilot, therefore, represents a continuum of Hanford's pioneering efforts to adapt chemical industry ESH practices, where relevant and applicable, to the site's operations.

\section{METHODOLOGY FOR HANFORD'S MSV PILOT}

\section{A. Context}

Since the objective of the pilot was to test the potential applicability of CMA's MSV approach at Hanford, the pilot focused only on a single ESH-related program at Hanford, the Project Hanford Management Contract (PHMC) CMS effort. This effort was chosen as the "test" program because: 1) it is a discreet, readily identifiable program, with significant visibility and momentum, within the PHMC; 2) it has potential site-wide and DOE complexwide impact; 3 ) it is a young and evolving program where the identification of "early indicators" of management systems success could be very helpful for its continued growth and implementation; and, 4) it is an exemplary voluntary effort undertaken by the major site contractors.

The purpose of the pilot was to test the potential applicability of the MSV process as a tool for evaluating management systems at Hanford and not to evaluate the CMS effort per se. As such, the pilot focused on evidencing management commitment and did not undertake a "technical" evaluation of the adequacy of the CMS. The pilot also focused only on the PHMC implementation of the CMS (FDH and the MSCs) and did NOT examine CMS implementation by other site major contractors (PNNL, Bechtel). Finally, the pilot was also suitably tailored to accommodate the significant operational differences between the chemical industry and DOE including; 1) the Management and Integration (M\&I) concept governing how work is done by the PHMC at Hanford; and, 2) the customer/client relationship of DOE-RL to the PHMC.

Furthermore, since it was envisioned that an MSV-like process might ultimately complement Hanford's ISMSV efforts, close coordination was undertaken with ISMS principals within DOE-RL and the PHMC during the development and implementation of the MSV Pilot.

In summary, the significant differences between the way in which Hanford's MSV Pilot was conducted and how the chemical industry typically conducts an MSV were as follows: . 
DOE/RL-98-80, Rev. 0

1. The MSV Pilot used a young and evolving ESH-related effort (CMS) as a test program whereas the industry MSV focuses on a mature ESH system.

2. The MSV Pilot focused on only one component (CMS) of Hanford's ESH management system, the ISMS, whereas the industry MSV examines a company's overall integrated ESH management system.

3. The MSV Pilot focused on management commitment relevant to the CMS whereas the industry MSV focuses on both management commitment and technical components relevant to an integrated ESH management system.

4. The purpose of the MSV Pilot was to evaluate the "value added" aspects of the MSV process as applied to Hanford (it did not attempt to evaluate the CMS effort per se) unlike the industry MSV whose purpose is to evaluate ESH management systems.

\section{B. Approach}

The overall approach for the conduct of the pilot was to follow the MSV protocol as much as practicable. As such, an MSV Verifier Team (Roger Briggs, DOE-RL; Lori Ramonas, Technical Resources International, Inc.; and William Westendorf, Link Technologies, Inc.), first reviewed relevant CMS documentation contained in the PHMC Team Chemical Management System Briefing Book including various RL policy setting letters, related performance agreements, Responsible Care $\otimes$ crosswalks, CMS requirements and verification checklists, and program plans. The MSV Verifier Team then interviewed four panels (two to four members each) of "functional teams" within DOE-RL, FDH (the PHMC), and PHMC sub-contractors who were directly involved with and/or responsible for the successful development and implementation of the CMS, to determine how the various policies, agreements and requirements were being implemented.

Specifically, there were a total of 12 panel participants with four representatives from DOE$\mathrm{RL}$, four representatives from $\mathrm{FDH}$, and one representative each from the following PHMC sub-contractors: 1) DynCorp; 2) Numatec Hanford Corporation; 3) B\&W Hanford Company; and, 4) Duke Engineering Services. Approximately half of the participants represented ESH management functions whereas the other half represented various line management functions. Two representatives were the ISMS leads for DOE-RL and FDH respectively. Each panel interview took two hours.

The MSV Verifier Team had significant collective experience in: 1) management systems development and implementation (two members were directly involved in the development of Responsible Care区, the ESH management system for the U.S. chemical manufacturing 
industry; 2) MSV (one member underwent CMA sponsored MSV training); and, 3) relevant ESH commercial and government practices (one member formerly worked with a major chemical company and a second member was a certified industrial hygienist with DOE ESH experience). One member of the MSV Verifier Team, with long-standing membership in and involvement with the local community, role played being a member of the informed Hanford public.

Questions were asked by the interview team to engage and facilitate discussion on the following management-related topics relevant to the CMS:

1. Assurance that the CMS effort is being or will be implemented.

2. Integration of the CMS effort into the site's overall ISMS effort.

3. Institutionalization of CMS implementation as a way of doing business.

4. Resource determination for CMS implementation.

5. Impediments to long-term commitment and progress regarding the CMS.

Panel participants were informed of the above-mentioned five topic areas for discussion prior to the interview. However, panelists were not given the more detailed list of questions, included in $A P P E N D I X C$, that the interviewers used as a guide to facilitate the semistructured interview process.

Although the interview process focused questions on management at a systems level for each panel, the process was "tailored," before and during the interview, to allow panelists the opportunity to focus on those areas of greatest personal interest, energy and impact to them.

Finally, an MSV Pilot Effectiveness Survey, included in $A P P E N D I X D$, was administered immediately following panel discussion in order to: 1) guarantee $100 \%$ response by participants; and, 2) capture panelists' first thoughts and impressions following the completion of the MSV process.

\section{EVALUATION OF PILOT EFFECTIVENESS}

The effectiveness of the pilot was gauged in the following three ways:

1. From quantitative and qualitative responses provided by panel participants in response to an MSV Pilot Effectiveness Survey; 
2. From collective observations of the interview team regarding panelist participation and process factors contributing to participatory engagement; and,

3. From the collective findings of the interview team regarding strengths and opportunities regarding CMS implementation.

\section{A. Participant Evaluation Surveys}

The MSV Pilot Effectiveness Survey attempted to capture both quantitative (Part I) and qualitative (Part II) impressions of the MSV process from panel participants.

In Part I, panelists were asked to rate the effectiveness of the MSV Pilot, on a scale of 1 to 5 , in addressing 17 key areas of management performance related to the CMS. The effectiveness rating scale was qualified as ranging from "not at all effective" (1) to "extremely effective" (5). The summary results indicated that each of the 17 identified areas received on average at least a "passing" or "acceptable" rating of 3.0 or greater. The following areas received a significantly higher $(>3.5)$ effectiveness rating:

1. Establishment of clear roles and responsibilities (Average rating: 3.8)

2. Senior management direction and leadership (Average rating: 4.1)

3. Management accountability (Average rating: 3.8)

4. Communication of CMS status/progress to the public (Average rating: 4.1)

No average rating was less than 3.0. There were no notable differences between how $R L$, FDH and the sub-contractors rated Part I nor were there notable differences between the evaluations of ESH management vs. line management.

A complete display of the quantitative results from Part I, illustrating the range of responses between and within various panels, can be found in APPENDIXE.

In Part II, panelists were asked to provide qualitative, narrative responses to six questions. The summary results, per individual question, are as follows: 
1. Did the MSV Pilot help to gauge overall management commitment related to the CMS effort?

\section{(10-yes, 1-no, 1-undecided)}

Overall, panelists' remarks indicated that questions relating to management ownership and commitment were germane, allowed opportunity to discuss barriers, and increased their understanding of senior management's responsibility for CMS implementation.

2. Would an internal report, that identified opportunities for improvement with respect to the management of the CMS, be useful? Please explain.

\section{(9-yes, 3-undecided)}

The vast majority of panelists felt that an INTERNAL report of this nature would allow for improvement with CMS implementation, especially if it addressed opportunities for improvement with management commitment.

3. Do you see any value added aspects of the MSV process for enhancing the ISMS verification process at Hanford? Please explain.

\section{(7-yes, 5-undecided)}

The majority of panelists believed the management accountability/commitment aspects of the MSV Pilot would be useful for Hanford's ISMS verification efforts. Those panelists who were "undecided" expressed lack of sufficient familiarity with ISMSV and/or questions regarding the likelihood of senior management involvement.

4. Did the MSV Pilot help to gauge overall opportunities for public outreach and involvement? Please explain.

\section{(5-yes, 2-no, 5-somewhat)}

Panelists responses were mixed on this question. Several individuals felt that the discussion did help to elucidate public outreach/involvement opportunities whereas an equal number of individuals felt that additional time/discussion spent on this topic was necessary before they could more appropriately evaluate it.

5. What suggestions do you have for improving the MSV Pilot?

Most of the comments received were "process improvement related", i.e., longer 
interview time, more focus on "measurable" responses to questions, more interviewees, more cross-functional panels within an individual company, etc. No one challenged the fundamental underlying concept of the pilot.

\section{Other comments?}

The eight individuals who chose to respond to this question offered positive comments that complimented the "open dialogue" approach towards gathering information and individual perspectives.

A complete list of all narrative responses from Part II can be found in APPENDIX F.

\section{B. Observations of Interview Team}

The MSV Verifier Team viewed the pilot as very successful for engaging participants in open-ended and meaningful discussion on the management aspects of the CMS.

Observations of the interview team regarding the participation of panelists follows:

1. All panelists actively participated.

(No panelist withheld comment or appeared uncomfortable participating in the discussion.)

2. The engagement of all four panels was interactive and energetic with the level of engagement intensifying during the two hour discussion.

(Panels had not "run out of steam" at end of the two hours.)

3. The level of participation was high.

( $86 \%-12$ participants out of 1.4 invitees.)

4. The role play of a member of the public as a part of the interview team added a valuable public perspective to the process.

(This was recognized by panelists and evidenced in their evaluation survey responses.)

5. Discussion was open-ended and frank.

(It represented an exchange of opinions vs. scripted, rehearsed answers to questions.)

6. Panelists were willing and comfortable offering different opinions.

(Panelists expressed opinions as individuals vs. organizational party lines.) 
In the opinion of the interview team, important process and other factors contributing to the successful participatory nature of the pilot were as follows:

1. The physical location set-up facilitated dialogue.

(Small table, appropriately sized room.)

2. The nature of the questions promoted discussion in the form of "telling of a story". (Focus on management at a systems level vs. specific processes and procedures.)

3. The interview process was deliberately "tailored" for each panel to allow panelists the opportunity to focus on those areas of greatest personal interest and impact to them.

4. The inclusion of a DOE-RL management panel helped to catalyze the high level of participation.

(DOE-RL is the "ultimate" customer for FDH and its sub-contractors.)

5. A semi-structured vs. prescriptive interview process facilitated free flowing discussion.

6. The types of questions asked open ended and non-threatening. (There were no "wrong" answers.)

7. Interviewers tried to be "non-judgmental" regarding responses to questions throughout the discussion.

\section{Summary of CMS Management System Strengths and Opportunities}

The sole purpose of the MSV Pilot was to evaluate the potential applicability of the MSV process, as an adjunct to ISMSV, at Hanford. However, since the vast majority of pilot participants requested feedback on strengths and opportunities regarding management system aspects of the CMS, an internal report which addresses these issues was produced. The following is a brief summary of the findings from that separate effort:

The CMS effort has many strengths. For example:

- The development of the CMS requirements was undertaken as a voluntary site-wide effort by the major site contractors.

- $\quad \mathrm{RL}$ and FDH management have visibly evidenced a commitment to the CMS by making 
it one of the top four ESH projects for FY'98.

- A formalization of CMS roles and responsibilities was well underway. As an example, a vital network of CMS Points of Contact had been established with FDH and the MSCs; and,

- Important baselining work has been undertaken including a gap analysis of CMS requirements and existing, related ESH programs.

The major management opportunities at this time include:

1. Continue and strengthen top management involvement, particularly line management in $\mathrm{RL}$ and $\mathrm{FDH}$, through visible and on-going communications relative to $\mathrm{CMS}$ implementation.

2. Incorporate CMS aspects into organizational and individual performance goals, starting with performance goals for $\mathrm{RL}$ and FDH senior management.

3. Strengthen management commitment, and perception of that commitment, to ISMS. Enhance understanding of ISMS, and CMS role within ISMS, throughout RL, PHMC and MSC organizations.

4. Proactively identify and enhance opportunities to expand open dialogue and involvement with workers and the public, regarding ISMS and CMS.

\section{LESSONS LEARNED}

Although there were numerous "lessons learned" of a process nature that would allow for a further fine-tuning of an MSV Pilot effort at a future date, those items are not the focus of this section. Members of the MSV Verifier Team instead identified the following fundamental "systems issues" that, in their collective opinion, are key for preserving the integrity and impact of the MSV process.

\section{INDEPENDENCE OF INTERVIEWERS}

The independence of interviewers is critical for success. That is, outside representatives who don't have oversight of, aren't regulating, and/or aren't internal to the organizations participating in the MSV process are more likely to be able to facilitate honest, open-ended dialogue because of the very nature of their independence, and perception of that independence, by participants. This is similar to the CMA MSV process where a team of external consultants and industry representatives from other 
companies is assembled as the interview or verifier team.

NOTE: The only "organizationally internal" interview team member, the DOE-RL representative, role played an external member of the public during the MSV Pilot.

\section{OPEN-ENDED, SEMI-STRUCTURED INTERVIEW PROCESS}

The key to success for initiating open dialogue is to employ an open-ended interview process. This means focusing on "how" questions and allowing panelists, within a given framework, to focus on those topics of greatest energy and interest to them. The questions that are developed to facilitate dialogue need to be carefully tailored so they have a relevance within the system being examined. This means the interview team needs to invest time reviewing key policies, principles and practices prior to visiting a site so they understand the dynamics and decision-making processes at that site. This also is similar to the CMA MSV process whereby the verifier team invests a significant amount of preparatory work prior to initiating the MSV process.

\section{PUBLIC PARTICIPATION}

The participation of a member of the public is an important and unique addition to the interview team. Although a member of the public was "role played" only during the MSV Pilot, it served to demonstrate to panelists the potential for building public trust. CMA member companies who have undergone an MSV review have often commented that including a member of the public was one of the most useful aspects of the MSV process.

NOTE: The success of including a public participant depends, in large measure, on the objectivity of the member of the public chosen. As is the case with the chemical industry, public participants should be chosen by the company/organization undergoing an MSV based on their ability to provide unbiased, constructive feedback.

\section{FRONT-END BUY-IN}

It is important to build front-end buy-in to maximize the benefit of the MSV process for participants. For example, several discussions were held over a period of several months at several different management levels at Hanford before the MSV Pilot was initiated. Also, internal FDH advocates were cultivated who were instrumental in generating broader internal support for the pilot, especially among the PHMC sub-contractors. This also is similar to the CMA MSV process where member chemical companies must self-initiate a request for an MSV and, as such, are interested in and committed to its success. 
A final observation of the MSV Verifier Team was that the MSV Pilot was neither excessively labor intensive nor time consuming. The interview team was comprised of only three members, which is typically the size of a CMA MSV team. Panel participants were required to only donate two hours of their time (this is somewhat less than what is typically required in a CMA MSV review whereby panel discussions are generally three to four hours in duration). Despite the "compactness" of the MSV Pilot, it was possible to initiate some very good thought-provoking discussions that, in turn, identified several key areas for management system improvement regarding the CMS.

\section{CONCLUSIONS}

The MSV, like the ISMSV, has as its foundation a comprehensive and systematic documentation review as initial evidence of the infrastructure necessary for a well functioning management system. Also like the ISMSV, the MSV process interviews individuals to better gauge the extent and vitality of management system implementation. The MSV process, however, differs from and can complement the ISMSV in that it: 1) employs a panel-to-panel dialogue approach; 2) involves a broad vertical cross-section of individuals from top management to workers in the field; and, 3) compels engagement of top management from the outset of the process.

The evaluation results from panel participants indicated that the MSV Pilot was particularly beneficial for:

1. Focusing on senior management direction, leadership, and accountability;

2. Focusing on clear roles and responsibilities;

3. Focusing on communication and public accountability; and,

4. Gauging overall management commitment.

An internal report was generated, at the request of Panel Participants, which identified existing strengths and additional management opportunities to better assure the sustainability and longterm viability of the evolving CMS effort.

The verifier team witnessed strong engagement and germane discussion, by all panel participants, on the development, integration, and effectiveness of management systems necessary for CMS implementation and continuous improvement. This evidenced the importance of and need for ongoing frank discussion on these topics.

In summary, given the strong and consistent theme involving management commitment and engagement that surfaced during the MSV Pilot, coupled with the following recent recommendations resulting from the K Basins ISMS Phase I Verification: 
DOE/RL-98-80, Rev. 0

- "DOE-RL and FDH need to increase the level of senior management attention and resources."

- "Senior management must demonstrate greater involvement and participation in future verification efforts."

the following "next step" MSV recommendation is made:

\section{- CONDUCT AN MSV, IN CONJUNCTION WITH AN ISMSV, TO ENGAGE MANAGEMENT AND GAUGE MANAGEMENT COMMITMENT.}

The MSV could be conducted as part of internal self-assessments efforts in preparation for ISMSV or as a separate "front-end" process in conjunction with the actual conduct of an ISMSV.

While the subjective and objective results that are presented in this report that address the effectiveness of the MSV Pilot are indeed encouraging, the ultimate test of success is whether the MSV process can improve ISMSV efforts. Compelling evidence as to the usefulness of the MSV process as an adjunct to ISMSV can only be obtained by linking the MSV process in the future specifically with an ongoing ISMSV effort. In this context, the scope of the MSV process could expand to cover the broad range of integrated ESH management, the purpose for which the MSV process is truly intended. 


\section{THE RESPONSIBLE CARE@ INITIATIVE}

There are 10 primary elements of CMA's Responsible Care $B$ which include:

1. GUIDING PRINCIPLES - Statements of philosophy and commitment regarding health, safety and environmental responsibilities in the management of chemicals. CMA member companies pledge to manage their businesses according to these principles.

1. CODES OF MANAGEMENT PRACTICES - The heart of Responsible Care $($ initiative is the six codes which address state-of-the-art "best practices" in specific areas of chemical manufacturing, transporting and handling that companies make continuous good-faith efforts to attain. The six codes are (in order of their development and subsequent approval): a) Community Awareness and Emergency Response; b) Pollution Prevention; c) Process Safety; d) Distribution; e) Employee Health and Safety; and, f) Product Stewardship.

2. PUBLIC ADVISORY PANEL - A group of health, safety and environmental thought leaders which assists the industry in identifying and developing programs and actions that are responsive to public concerns.

3. MEMBER SELF-EVALUATIONS - Self-evaluations are reported annually to CMA by each member company on each code. The self-evaluations are a valuable management tool which provide a measure of individual member company progress and help CMA appropriately direct mutual assistance efforts.

4. MEASURES OF PERFORMANCE - Tangible performance measures have been developed for each code to help the industry and the public better understand the progress being made under Responsible Care $\$$.

5. MANAGEMENT SYSTEMS VERIFICATTON*** - A MSV process has recently been developed, which includes appropriate public involvement, to assist member companies with ESH performance improvement.

6. EXECUTIVE LEADERSHIP GROUPS - Industry executives meet regularly to share experiences, review progress and identify areas where assistance is needed. This forum is an important "peer pressure" mechanism for maintaining momentum and commitment by industry senior management.

7. MUTUAL ASSISTANCE - Member companies must help one another in implementing all aspects of Responsible Care 8 . Mutual assistance focuses on direct networking at 
DOE/RL-98-80, Rev. 0

executive, management and practitioner levels.

8. PARTNERSHIP PROGRAM - This program provides an opportunity for non-CMA companies to become involved in the Responsible Careß initiative.

9. OBLIGATION OF MEMBERSHIP - Bylaws obligate CMA member companies to participate in all elements of the Responsible Care $B$ initiative. 
DOE/RL-98-80, Rev. 0

APPENDIX B

\section{THE CMA MANAGEMENT SYSTEMS VERIFICATION (MSV) CORE ELEMENTS AND ATTRIBUTES}

\section{A. POLICY AND LEADERSHIP}

This management element addresses the leadership exhibited by senior management in setting clear policy and guidelines for performance, and for enhancing the value of the Responsible Care ${ }^{l}$ ethic within the organization.

\section{Attributes}

Senior management demonstrates leadership and commitment for their organization (company, plant or business unit) by active participation in the creation and implementation of a clear and visible policy that:

A.1 is relevant to the nature and scale of the organization's products and processes,

A.2 fosters openness in dealing with stakeholders and takes into account public and employee inputs,

A.3 includes a commitment to continual improvement of the management of chemicals and sets a framework for reviewing and establishing Responsible Care objectives and targets,

A.4 includes a commitment to comply with relevant legislation and regulations,

A.5 reflects the company's commitment to the Guiding Principles of Responsible Care 8 ,

A.6 is documented, maintained and communicated to employees, and

A.7 provides adequate staffing and resources for the proper implementation of the policy and the Responsible Care initiative.

\section{B. PLANNING}

This management element addresses; 1 ) the identification and assessment of relevant regulations and industry standards, 2) the evaluation of product, process and distribution risks, 3) the identification and assessment of employee and community concerns about the organization's environmental, health and safety performance, and 4) setting priorities and goals for performance improvement.

${ }^{1}$ NOTE - Since the CMA MSV process was built around the Responsible Care® initiative, the initiative is referenced frequently throughout. However, one can easily replace "Responsible Care ( with "integrated ESH management system" for relevance within the DOE system. 


\section{Attributes}

The organization demonstrates appropriate planning by:

B.1 having processes in place for the assessment of hazards and risks associated with their products, processes and distribution activities that includes impact on the environment, personnel and communities,

B.2 integrating the risk evaluation process into the research and development of new products and processes,

B.3 creating and maintaining a product information system related to environmental, health and safety risks,

B.4 having processes in place for the systematic review of all environmental, health and safety related regulations, and their interpretations, that are relevant to the organization's activities,

B.5 maintaining documented Responsible Care objectives and targets which have clear means, timeframes, and responsibilities for accomplishment,

B.6 having a system in place for the identification of needs and allocation of resources to implement performance improvements, and

B.7 having processes in place to assess community and employee concerns about the organization's activities.

\section{IMPLEMENTATION, OPERATION AND ACCOUNTABILITY}

This management element addresses the achievement of objectives and policy expectations. It also covers the preparation and competence of employees to carry out their tasks, and documentation that is critical to the execution of those tasks.

\section{$\underline{\text { Attributes }}$}

The organization demonstrates that implementation, operation and accountability are part of their management system by the existence of:

C.1 a clear definition of responsibility and accountability for the execution of Responsible Care(is tasks,

C.2 training programs that include task specific skills and competencies, and awareness of regulatory requirements appropriate to the task,

C. 3 a process for communication and dialogue with stakeholders of relevant risks and impacts of the organization's activities to human health and the environment, and plans for improving the organization's Responsible Care $B$ management system,

C.4 employee involvement in the development, communication and execution of Responsible Care $\otimes$ programs,

C.5 documented procedures to ensure safe operations for all processes, process changes, maintenance, and product handling and storage, 
C.6 written site emergency response plans with appropriate considerations of communications and community recovery needs,

C.7 participation in the development of community emergency preparedness planning,

C.8 a documented process for responding to chemical distribution incidents,

C.9 programs to provide appropriate guidance, information and training requirements to carriers, distributors, customers and contractors on the risks and hazards of the organization's products and processes, and for receiving guidance and information from suppliers on goods and services used by the organization,

C.10 processes for the qualification and selection of carriers, distributors and contractors that place priority on safety performance, and

C.11 clearly defined and visible emissions reduction, pollution prevention, and ground water protection programs.

\section{PERFORMANCE MEASUREMENT AND CORRECTIVE ACTION}

This management element deals with the use of performance indicators, performance reviews, accident and incident investigation, compliance audits, data records, and taking or recommending corrective actions.

\section{Attributes}

The organization demonstrates the use of performance measurement and corrective action by having processes in place for:

D.1 the tracking of emissions and releases, accidents and injuries, process upsets, and distribution incidents,

D.2 reviewing the performance of all carriers, suppliers, distributors, customers and contractors,

D.3 the investigation of accidents and incidents that get at the root causes of the occurrence and develop recommendations for prevention or corrective action,

D.4 the maintenance of sufficient data files to enable analysis of trends and performance against goals,

D.5 the audit or review of compliance with regulations and company procedures, and

D. 6 the measurement of the effectiveness of its communications programs with its stakeholders.

\section{E. MANAGEMENT REVIEW AND REPORTING}

This management element addresses the manner in which the organization reports its performance to its stakeholders and senior management, and how the organization and senior management reviews that performance relative to goals and makes appropriate changes in goals, policies or priorities. 
Attributes

Management Review and Reporting are characterized by evidence of:

E.1 periodic reviews of the organization's objectives and policies for relevance against the organization's products and processes, the expectations of stakeholders, the adequacy of resources assigned to Responsible Care management programs, and the organization's performance against their goals and policies,

E.2 reporting mechanisms to stockholders, employees and communities on the organization's Responsible Care\& results,

E.3 benchmarking of Responsible Care $B$ management systems against other organizations, and

E.4 a performance management system for employees that recognizes Responsible Care $\beta$ excellence. 
DOE/RL-98-80, Rev. 0

APPENDIX C

\section{INTERVIEW QUESTIONS FOR HANFORD'S MSV PILOT}

1. Could you define what the CMS is and its relevance to you, your organization, and the PHMC?

2. Could you describe the way your organization is/will be structured to effectively implement the CMS?

- Roles/Responsibilities?

- Relationship of FDH/sub-contractors?

- Accountability?

- CMS "stewards"?

2a. For FDH: How do/will you assure contractor conformance/compliance?

3. Could you describe your process for identifying the resources needed and staffing required for CMS requirement implementation at the FDH, MSC, subcontractor, and facility levels?

- Review with peers in sub-contractor organizations?

- $\quad$ Asking staff for input?

3a. For contractor CMS points-of-contact: Do you have the necessary resources for the CMS (dollars, labor hours, direct access to decision-making authorities, etc.) and/or authority to secure necessary resources?

3b. Is the process for disseminating a new program and/or requirements among the PHMC formal, (e.g., are there procedures or management directives which dictate the process which needs to be followed)? For this process, formal or informal, what is going well and what could be better?

4. How will you determine if the resources applied to implementation of the CMS and the attainment of CMS objectives are adequate?

- Results?

- Senior management review?

- Industry benchmarking?

5. How are you assuring that within the context of the M\&I contract to what extent a new effort like the CMS really is implemented? (i.e., how does work really take place?)

6. To what extent is the CMS effort being integrated into the ISMS? How are you assuring that this integration effort preserves a cohesive and comprehensive CMS approach? 
7. To what extent is the CMS concept being integrated into existing training and how is this being translated into conduct of operations?

8. What process will your organization use to periodically review your CMS requirements for relevance and appropriateness?

- Senior management review?

- Benchmarking with industry?

- Other?

9. Could you describe how you will continue to externally benchmark your CMS activities with industry?

- $\quad$ Comparison of management systems?

- Comparison of performance/results?

10. What will you use as performance measures to determine the adequacy of the CMS? (i.e., how do you as a manager or as a worker know if you are doing a good job?)

11. How will your organization internally review and discuss your CMS performance?

- ESH Management Council?

- Department meetings?

- $\quad$ Staff meetings?

12. Will you include CMS performance in your employee performance evaluations?

- Promotions?

- Merit increases?

- Special forms of recognition?

13. How will you ensure that the CMS effort will be sustained beyond this initial developmental stage and institutionalized as a way of doing business?

- Institutional and individual performance goals?

- Contractual obligations w/sub-contractors?

- Budget allocations specifically earmarked for CMS?

14. Are there any barriers that may impede long-term commitment to and progress regarding the CMS?

15. How are you assured that you have adequate communication and integration with DOE-RL regarding the CMS? How are you assured that you have DOE-RL commitment at both the ESH and project levels?

16. Could you describe your personal role in the communication of your commitment and priorities relative to the CMS? 
17. During this development/initial implementation phase of the CMS, what processes are you going through to take into account public and employee needs?

18. How will you identify and assess employee and community/public needs, regarding the CMS, on an ongoing basis?

- $\quad$ Part of ISMS efforts?

- Separate?

19. Could you describe your process for internally communicating CMS requirements?

- With employees?

- With sub-contractors?

20. What plans do you have for working in partnership with DOE-RL's Office of External Affairs for ongoing external communications and outreach efforts associated with the CMS?

- With the community?

- With other interested external stakeholders?

21. How do you plan to assist DOE-RL's Office of External Affairs in measuring the effectiveness of communications and outreach efforts related to the CMS? 


\section{MSV PILOT EFFECTIVENESS SURVEY}

\section{Part I}

Please indicate your perceptions of the effectiveness of the MSV Pilot, as a tool for focusing on management involvement and commitment in the context of the CMS effort, using the rating scale provided below. Your answers will be kept completely confidential -- only general summaries of major trends and themes will be prepared. Please feel free to write in, and rate, relevant issues or performance areas that are not addressed in the survey. Indicate "NA" (No Answer) if you do not have an opinion or do not wish to provide a rating for any item.

\section{Effectiveness Rating Scale:}

1

Not at all effective
2

Slightly effective
3

Somewhat

effective
4

Moderately

effective
5

Extremely

effective

Effectiveness of MSV Pilot in Focusing on the Following Areas of Management Performance Related to the CMS:

Effectiveness:

1. Establishment of clear roles and responsibilities.

$\begin{array}{llllll}1 & 2 & 3 & 4 & 5 & \mathrm{NA}\end{array}$

2. Senior management direction and leadership.

$\begin{array}{llllll}1 & 2 & 3 & 4 & 5 & \text { NA }\end{array}$

3. Communication of a clear vision for the future.

$\begin{array}{llllll}1 & 2 & 3 & 4 & 5 & \text { NA }\end{array}$

4. Strategic prioritization of activities.

$\begin{array}{llllll}1 & 2 & 3 & 4 & 5 & \mathrm{NA}\end{array}$

5. Management accountability.

6. Review and feedback on CMS performance.

$\begin{array}{llllll}1 & 2 & 3 & 4 & 5 & \mathrm{NA}\end{array}$

7. Use of budget resources.

8. Project management.

9. Accomplishment of objectives.

10. Providing clear direction to the contractor.

$\begin{array}{llllll}1 & 2 & 3 & 4 & 5 & \mathrm{NA}\end{array}$

$\begin{array}{llllll}1 & 2 & 3 & 4 & 5 & \mathrm{NA}\end{array}$

11. RL management performance.

$\begin{array}{llllll}1 & 2 & 3 & 4 & 5 & \text { NA }\end{array}$

12. PHMC management performance.

$\begin{array}{llllll}1 & 2 & 3 & 4 & 5 & \mathrm{NA}\end{array}$

$\begin{array}{llllll}1 & 2 & 3 & 4 & 5 & \text { NA }\end{array}$

13. Contractor management performance.

$\begin{array}{llllll}1 & 2 & 3 & 4 & 5 & \mathrm{NA}\end{array}$

14. Communication, partnership with DOE-RL.

$\begin{array}{llllll}1 & 2 & 3 & 4 & 5 & \mathrm{NA}\end{array}$

15. Communication, partnership with PHMC.

16. Communication, partnership with contractors.

$\begin{array}{llllll}1 & 2 & 3 & 4 & 5 & \mathrm{NA}\end{array}$

$\begin{array}{llllll}1 & 2 & 3 & 4 & 5 & \mathrm{NA}\end{array}$

$\begin{array}{llllll}1 & 2 & 3 & 4 & 5 & \text { NA }\end{array}$

17. Communication of CMS status, progress to the public.

$\begin{array}{llllll}1 & 2 & 3 & 4 & 5 & \mathrm{NA}\end{array}$

$\begin{array}{lllllll}1 & 2 & 3 & 4 & 5 & \mathrm{NA}\end{array}$ 


\section{$\underline{\text { Part II }}$}

In this section, please provide qualitative, narrative responses to the following questions:

1. Did this MSV Pilot help to gauge overall management commitment related to the CMS effort? Please explain.

2. Would an internal report, that identified opportunities for improvement with respect to the management of the CMS, be useful? Please explain.

3. Do you see any value added aspects of the MSV process for enhancing the ISMS verification process at Hanford? Please explain.

4. Did this MSV Pilot help to gauge overall opportunities for public outreach and involvement? Please explain.

5. What suggestions do you have for improving the MSV Pilot?

6. Other comments? 


\section{PARTICIPANT EVALUATION SURVEYS - PART I}

Code:

Group I - FDH Management

Group II - RL Management

Group III - Major Subcontractors

Effectiveness Rating Scale:

1

Not at all effective
3

Slightly effective

Somewhat

effective
4

Moderately

effective
5

Extremely

effective

Effectiveness of MSV Pilot in Focusing on the Following Areas of Management Performance Related to the CMS:

1. Establishment of clear roles and responsibilities.

\begin{tabular}{|c|c|c|c|c|}
\hline Rating & Group I & Group II & Group III & $10 \mathrm{TAL}$ \\
\hline 1 & & & & \\
\hline 2 & & & & \\
\hline 3 & 1 & 1 & 2 & 4 \\
\hline 4 & 2 & 2 & & 4 \\
\hline 5 & 1 & 1 & & 2 \\
\hline NA & & & 2 & 27 \\
\hline
\end{tabular}

AVERAGE: 3.8

2. Senior management direction and leadership.

\begin{tabular}{|l|l|l|l|l|}
\hline Rating & Group I & Group I & Group II & roT 4 LS \\
\hline 1 & & & & \\
\hline 2 & & & & \\
\hline 3 & 1 & & & \\
\hline
\end{tabular}

\begin{tabular}{|l|l|l|l|l}
\hline 4 & 2 & 4 & 3 & 9 \\
\hline 5 & 1 & & 1 & \\
\hline NA & & & &
\end{tabular}

AVERAGE: 4.1

3. Communication of a clear vision for the future.

\begin{tabular}{|c|c|c|c|c|}
\hline Rating & Gtoup I & Group II & Group III & sor $/ 4$ \\
\hline \multicolumn{5}{|l|}{1} \\
\hline 2 & 1 & & & 1 \\
\hline 3 & 3 & 2 & 1 & 6 \\
\hline 4 & & 2 & 2 & 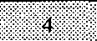 \\
\hline \multicolumn{5}{|l|}{5} \\
\hline NA & & & 1 & 1 \\
\hline
\end{tabular}

AVERAGE: 3.3

4. Strategic prioritization of activities. 
DOE/RL-98-80, Rev. 0

\begin{tabular}{|l|l|l|l|l|}
\hline Rating & Group I & Group I & Group II & rot A S \\
\hline 1 & & & & \\
\hline 2 & & & 2 & \\
\hline 3 & 3 & 4 & & \\
\hline 4 & 1 & & 2 & \\
\hline 5 & & & & \\
\hline NA & & & & \\
\hline
\end{tabular}

AVERAGE: 3.1

5. Management accountability.

\begin{tabular}{|c|c|c|c|c|}
\hline Rating & Group I & Group II & Group III & ToT $1 \mathrm{~s}$ \\
\hline 1 & & & & \\
\hline 2 & 2 & & & 2 \\
\hline 3 & & & 1 & ) \\
\hline 4 & 1 & 3 & 2 & 6 \\
\hline 5 & 1 & 1 & 1 & 3 \\
\hline NA & & & & \\
\hline
\end{tabular}

AVERAGE: 3.8

6. Review and feedback on CMS performance.

\begin{tabular}{|c|c|c|c|c|}
\hline Rating & Group I & Group II & Group III & Tom $1 \mathrm{~s}$ \\
\hline \multicolumn{5}{|l|}{1} \\
\hline \multicolumn{5}{|l|}{2} \\
\hline 3 & 3 & 1 & 3 & 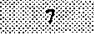 \\
\hline 4 & & 2 & & 2 \\
\hline 5 & 1 & 1 & & 2 \\
\hline $\mathrm{NA}$ & & & 1 & 1 \\
\hline
\end{tabular}

\section{AVERAGE: 3.5}

7. Use of budget resources.

\begin{tabular}{|c|c|c|c|c|}
\hline Rating & Group I & Group II & Group III & $101 \% 4$ \\
\hline \multicolumn{5}{|l|}{1} \\
\hline 2 & 1 & & & \% \\
\hline 3 & 1 & 2 & & 8 \\
\hline 4 & 2 & 2 & 3 & X \\
\hline \multicolumn{5}{|l|}{5} \\
\hline NA & & & 1 & 1 \\
\hline
\end{tabular}

AVERAGE: 3.5

8. Project management.

\begin{tabular}{|c|c|c|c|c|}
\hline Rating & Group I & Group II & Group III & $100 \% 1 \%$ \\
\hline 1 & & & 1 & K \\
\hline 2 & 1 & 1 & & 2 \\
\hline 3 & 2 & 1 & 1 & 4 \\
\hline 4 & 1 & 1 & & $\%$ \\
\hline 5 & & 1 & & V \\
\hline NA & & & 2 & \% \\
\hline
\end{tabular}

AVERAGE: 3.0

9. Accomplishment of objectives.

\begin{tabular}{|c|c|c|c|c|}
\hline Rating & Group I & Group II & Group III & rot 4 Ls \\
\hline 1 & & & 1 & y \\
\hline 2 & 1 & & & y \\
\hline 3 & 2 & 2 & & 4 \\
\hline 4 & 1 & 2 & 3 & 6 \\
\hline 5 & & & & ڤ \\
\hline$N A$ & & & & 1 \\
\hline
\end{tabular}

AVERAGE: 3.3 
DOE/RL-98-80, Rev. 0

10. Providing clear direction to the contractor.

\begin{tabular}{|c|c|c|c|c|}
\hline Rating & Group I & Group II & Group III & 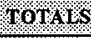 \\
\hline \multicolumn{5}{|l|}{1} \\
\hline 2 & & & 1 & 1 \\
\hline 3 & 3 & 3 & & 6 \\
\hline 4 & 1 & 1 & 2 & 4 \\
\hline \multicolumn{5}{|l|}{5} \\
\hline $\mathrm{NA}$ & & & 1 & 1 \\
\hline
\end{tabular}

AVERAGE: 3.3

11. RL management performance.

\begin{tabular}{|c|c|c|c|c|}
\hline Rating & Group I & Group II & Group III & 101815 \\
\hline 1 & & & & \\
\hline 2 & & & 2 & 2 \\
\hline 3 & 3 & & & 3 \\
\hline 4 & & 2 & 1 & 3 \\
\hline 5 & & 2 & & 2 \\
\hline NA & 1 & & 1 & 2 \\
\hline
\end{tabular}

AVERAGE: 3.5

12. PHMC management performance,

\begin{tabular}{|c|c|c|c|c|}
\hline Rating & Group I & Group II & Group III & TOTALS \\
\hline I & & & & \\
\hline 2 & 1 & & & 1 \\
\hline 3 & 2 & 2 & 2 & 6 \\
\hline 4 & 1 & 1 & 2 & 4 \\
\hline 5 & & 1 & & 3 \\
\hline
\end{tabular}

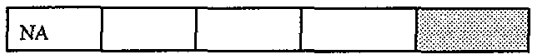

AVERAGE: 3.4

13. Contractor management performance.

\begin{tabular}{|c|c|c|c|c|}
\hline Rating & Group I & Group II & Group III & MOTH LS \\
\hline 1 & & & & \\
\hline 2 & 1 & & 1 & 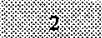 \\
\hline 3 & 2 & 2 & 1 & 5 \\
\hline 4 & & 2 & 2 & 4 \\
\hline 5 & 1 & & & 1 \\
\hline NA & & & & \\
\hline
\end{tabular}

AVERAGE: 3.3

14. Communication, partnership with DOE-RL.

\begin{tabular}{|c|c|c|c|c|}
\hline Rating & Group I & Group II & Group III & $107 \mathrm{ks}$ \\
\hline I & & . & 1 & x \\
\hline 2 & 1 & & 2 & 3 \\
\hline 3 & 1 & & & 1. \\
\hline 4 & 2 & 3 & & 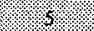 \\
\hline 5 & & & 1 & xis \\
\hline NA & & 1 & & 1 \\
\hline
\end{tabular}

\section{AVERAGE: 3.2}

15. Communication, partnership with PHMC.

\begin{tabular}{|l|l|l|l|l|}
\hline Rating & Group I & Group II & Group III & roI A LS \\
\hline 1 & & & & \\
\hline 2 & 2 & 1 & 2 & \\
\hline 3 & & 1 & & \\
\hline
\end{tabular}




\begin{tabular}{|c|c|c|c|c|}
\hline 4 & & 2 & & 2 \\
\hline 5 & & & 2 & 2 \\
\hline NA & 2 & & & 2 \\
\hline
\end{tabular}

AVERAGE: 3.1

16. Communication, partnership with contractors.

\begin{tabular}{|c|c|c|c|c|}
\hline Rating & Group I & Group II & Group III & $901 \% 15$ \\
\hline 1 & & & & \\
\hline 2 & 1 & 1 & 1 & 3 \\
\hline 3 & 2 & 2 & 1 & 5 \\
\hline 4 & & 1 & 1 & 2 \\
\hline 5 & 1 & & 1 & 2 \\
\hline NA & & & & \\
\hline
\end{tabular}

AVERAGE: 3.3

17. Communication of CMS status, progress to the public.

\begin{tabular}{|l|l|l|l|l|}
\hline Rating & Group I & Group I & Group II & IOTLS \\
\hline 1 & & & & \\
\hline 2 & & & 1 & \\
\hline 3 & 1 & & & \\
\hline 4 & 2 & 3 & 1 & 0 \\
\hline 5 & 1 & 1 & 2 & 4 \\
\hline NA & & & & \\
\hline
\end{tabular}

AVERAGE; 4.1 
DOE/RL-98-80, Rev. 0

APPENDIX F

\section{PARTICIPANT EVALUATION SURVEYS - PART I RESULTS}

Code:

Group I - FDH Management

Group II - RL Management

Group III - Major Subcontractors

1. Did this MSV Pilot help to gauge overall management commitment related to the CMS effort? Please explain.

\section{GROUP I}

- Yes. Questions were posed as to levels of management commitment and management evaluation.

- Yes. Several of the questions focused on the degree of management (both FDH and DOE-RL) commitment to the CMS.

- No. I felt like I was explaining not focusing on the topic for any other reason.

- Yes. Discussion of prioritization and commitments relative to CMS.

\section{GROUP II}

- It helped with my understanding of senior management's division of responsibility for implementation of CMS.

- Interviewers asked and got responses to several penetrating questions relating to management ownership and commitment.

- Yes. Given CMS as part of ISMS. Focus on accountability/drivers was good.

- In part, it would have helped to have had one AM in attendance.

\section{GROUP III}

- Yes. It did help gauge overall commitment, but the questions and discussion did not directly evaluate the depth and breadth of management commitment.

- Yes. While management commitment is likely strong, it needs higher visibility.

- Yes. Clarified that this could die if perceived as the flavor of the month. Not $100 \%$ of management commitment/wait and see.

- Yes. There was a great opportunity to discuss specific barriers to sustained commitment. Tips for avoiding problems of the past were discussed. 
2. Would an internal report, that identified opportunities for improvement with respect to the management of the CMS, be useful? Please explain.

\section{GROUPI}

- Yes. After a significant amount of CMS implementation has been accomplished:

- Yes. Especially if it focused on management and resource commitments (or lack thereof).

- Who would write the report? What's the scope?

- Yes. There is always room for improvement. I would be interested in a summary from the various panels (i.e., RL, us, FDH).

\section{GROUP II}

- Potentially yes. I would like to see the report and then judge its usefulness.

- N/A

- Yes. Internal reports based on thorough questioning to allow improvement is always good.

- Yes. Could be used as a basis for scheduling oversight activities in regards to CMS.

\section{GROUP III}

- Yes. As noted during the discussion, I believe the implementation plan should identify actions to evaluate the effectiveness of system components currently in place. That evaluation could identify improvement opportunities.

- Yes but not now. This should come from the annual reviews that are part of the CMS requirements. A brief discussion of what knowledge was gained from this process should be provided.

- Yes. It would be a worthwhile effort to take to the facility. (Management report opportunities of improvement.)

- Yes. I am committed to CMS and want to know how this pilot went.

3. Do you see any value added aspects of the MSV process for enhancing the ISMS verification process at Hanford? Please explain.

\section{GROUP I}

- Yes. We need focus on specific areas like CMS to truly make ISMS verification a more useful step in enhancing our processes.

- Not sure unless the MSV involves senior management.

- Perhaps if the discussion was focused toward problem solving rather than discussion.

- N/A. I'm not familiar enough with the ISMS verification process to know. 


\section{GROUP II}

- The interview process might be a useful front end to ISMS verification. Also, involvement of Dick Belsey, someone similar from the HAB in Phase II has potential merit.

- MSV would be valuable if its process steps can align and provide the appropriate be products that might be used in ISMS verification. Otherwise it will tend to ultimately fragment the ISMS process that we have embarked upon. ISMS should integrate this MSV process.

- Yes. Accountability focus would help the ISMS verification process.

- Can't judge this. ISMS at Hanford is a big "beast". The resources involved in getting a good perspective on ISMS implementation would be massive.

\section{GROUP III}

- Yes. It could be used as a tool to gauge implementation.

- It is still unclear how the MSV process is different from a management assessment. Seems the questions/topic areas could easily be folded into existing assessment processes.

- Yes. Can be used as a tool to evaluate how well ISMS is understood at multiple levels of facility. Could be used to judge worker level perception of management commitment.

- Yes. Potentially if management commitment from DOE down is an ongoing priority/ "communication"

4. Did this MSV Pilot help to gauge overall opportunities for public outreach and involvement? Please explain.

\section{GROUP I}

- Yes. Made us think about opportunities where appropriate enhancement would be gained through public involvement.

- Not to any large extent. It helped identify deficiencies but not necessarily opportunities.

- No. I felt like I was explaining not focusing on the topic for any other reason.

- I don't think so. We discussed it some, but don't believe enough to "gauge overall opportunities".

\section{GROUP II}

- This is a little ambitious. It did give us an opportunity to review what has been done.

- To some extent. But this requires additional time.

- Yes. Although it really validated efforts we have begun.

- Somewhat. Could be expanded more. My impression was that we didn't spend a lot of time in this area.

\section{GROUP III}

- The "community" representative was effective in asking questions that prompted ideas for community 
involvement.

- Marginally. While discussed, no real conclusions reached.

- Yes. Discussed need to inform public of why site is doing CMS vs. have to due. Suggest show benefits.

- Yes. The need for positive communication to the public was discussed. The role of a public representative was a positive influence.

5. What suggestions do you have for improving the MSV Pilot?

\section{GROUP I}

- Performance indicators or performance measures to set and effectively measure/monitor system improvements is so important. You introduced it, but it will make or break us in the future.

- Discuss the intent and desired outcome of the pilot more extensively and review the survey prior to beginning the pilot.

- Focus your discussions toward a specific outcome. Develop questions with measurable responses.

- Less questions for the time involved, or less topics.

\section{GROUP II}

- So we can do another MSV Pilot? What I want to see is any suggestions for improving ISMS implementation/verification.

- Consider repeating interview after several months.

- Suggest additional aggressiveness on accountability questions (or any other deficient areas) to better illuminate deficiencies.

- Broader number of interviewees that would represent more of a cross-section of the operation/organization.

\section{GROUP III}

- Pilot was ok for this particular situation, but it would have had greater value to have participants represent the same company or at least different functional/line areas to obtain a greater diversity of viewpoints.

- Seems we ended up with a better evaluation of CMS to date though this is opposed to the process. However, the process did create some ideas for better institutionalizing ISMS/CMS through specific performance goals for certain individuals responsible for operations using chemicals.

- Nothing to judge against. Question is what will be done with the results.

- None

\section{Other comments?}

\section{GROUP I}


- Liked the "open dialogue" approach.

- The session was too loosely structured. Good sharing of perspectives, however, difficult to measure the effectiveness.

- Good luck with the other panels!

\section{GROUP II}

- Please provide your interview and final reports.

- Thanks.

\section{GROUP III}

- Facilitators were effective in putting participants at ease and in keeping the discussion moving. Good focus - accomplished a lot in a short time.

- Good approach to gather information.

- Thank you for your interest. I see great value in the MSV. 
DOE/RL-98-80, Rev. 0

\section{DISTRIBUTION}

Department of Energy - Richland Operations

Briggs, C.R. (10 copies)

DOE Reading Room

A5-55

Hanford Technical Library

H2-53

P8-55

Lockheed Martin Services, Inc.

Document Processing Center

A3-94 


\section{DISTRIBUTION}

Department of Energy - Richland Operations

Briggs, C.R.

DOE Reading Room

A5-55

Hanford Technical Library

$\mathrm{H} 2-53$

P8-55

Lockheed Martin Services, Inc.

Document Processing Center

A3-94 